\section{Clinical Evaluation of the Whitening Effect of Over-the- Counter Dentifrices on Vital Teeth}

Bruna Andrade Horn ${ }^{1}$, Bruna Fortes Bittencourt², Osnara Maria Mongruel Gomes $^{2}$, Patrícia Almeida Farhat ${ }^{1}$

\author{
'Department of Dentistry. CESCAGE \\ - Campos Gerais Higher Education \\ Center, Ponta Grossa, PR, Brazil \\ ${ }^{2}$ Department of Dentistry. UEPG - \\ State University of Ponta Grossa, \\ Ponta Grossa, PR, Brazil \\ Correspondence: Bruna Fortes \\ Bittencourt, Rua Santos Dumont, \\ 1331, Centro, 84010-360 Ponta \\ Grossa, PR, Brasil. Tel.: +55-42-3224- \\ 5164. e-mail: brubita@hotmail.com
}

Key Words: tooth bleaching, dentifrices, tooth brushing, spectrophotometer.

\begin{abstract}
This randomized clinical trial evaluated the whitening potential of commercially available toothpastes. Sixty patients were selected and randomly divided into 4 groups $(n=15)$, according to the dentifrice used: Gl (control) - Colgate Total 12, Gll - Close-up White Now, Glll: Oral-B 3D White, GIV: Colgate Luminous White. Three daily brushings were performed for 2 to 3 min each, during a period of 15 days. Patients had the color of their teeth evaluated before and after the treatment by means of a spectrophotometer (Vita EasyShade - CIE L*a*b*). Data obtained from $\mathrm{L}$ values were analyzed by one-way ANOVA and $t$ test. $\Delta \mathrm{E}$ was also evaluated to calculate color alteration, by NBS criteria. Mean (standard deviation) of initial values were Gl: 82.9 (4.9); Gll: 83.9 (5.8); Glll: 83.9 (7.2); GIV: 86.4 (3.4) and final values were Gl: 84.1 (6.3); Gll: 84.6 (6.1); GIII: 84.2 (7.1); GIV: 88.2 (2.8). In conclusion, the dentifrices showed no lightening action on vital teeth, except for Colgate Luminous White; but according to NBS criteria, there was no noticeable visible change to the patients in any group.
\end{abstract}

\section{Introduction}

Over the past few years, discolored teeth became one of the most frequent complaints of patients in dental offices. The preference for bright white teeth (1) and great appeal for esthetics in the media have contributed to increase the demand for tooth bleaching in the dental offices (2). In addition to the bleaching techniques performed or supervised by dentists, such as at-home and in-office bleaching therapies, there is a growing market for tooth whitening products that promise rapid and convenient bleaching, including whitening dentifrices (3).

Some of these dentifrices have hydrogen peroxide in their composition, whereas others act removing extrinsic stains by abrasive action. The most common abrasives are hydrated silica, calcium carbonate, aluminum oxide, dehydrated calcium phosphate and perlite (4). These dentifrices appear to have limited effectiveness, since they contain abrasives that work only at removing extrinsic stains instead of changing the color of a natural tooth as in a real whitening action. This mechanism should not be confused with bleaching action, which consists of free radicals breaking down pigments of discolored teeth $(5,6)$.

In vitrostudies (7-9) show that brushing with toothpaste containing bleaching products do not promote significant results in discolored teeth compared to conventional dentifrices, concluding that these dentifrices, due to their mechanical action (abrasion) and the increase of high-performance abrasives as hydrated silica, act just at removing pigmentation, giving a false sense of whitening. Studies also reveal that certain whitening dentifrices containing hydrogen peroxide and carbamide may produce lesions on the enamel surface (10-12). However, there are few studies addressing the clinical efficacy of whitening dentifrices (13-15).

The aim of this randomized clinical trial was to evaluate the whitening potential of three toothpastes, available and accessible to the population. The null hypothesis tested is that toothpastes do not produce tooth color alterations.

\section{Material and Methods}

\section{Study Design}

The experimental design followed the CONSORT statement (16). The study was a randomized clinical trial, performed at a private School of Dentistry in Ponta Grossa, PR, Brazil. The research protocol was approved by the local Ethics Committee (Plataforma Brazil - \#378.415).

\section{Selection of Participants}

Sixty undergraduate dental students volunteered for the study, forming a convenience sample. Before starting the treatment, all volunteers filled out forms containing personal data and each one signed an informed consent form. Two calibrated dental clinicians selected the participants according to inclusion and exclusion criteria. The subjects were required to be at least 18 years old, non-smokers, with good oral and general health and oral hygiene, vital anterior maxillary and mandibular teeth free of caries or restorations, no cervical lesions and no periodontal disease. Pregnant or breastfeeding women, individuals with discolored teeth caused by tetracycline, 
fluorosis, hyperplasia, endodontic treatment (or requiring endodontic treatment), restorations in anterior teeth, parafunctional habits or tooth sensitivity were excluded.

\section{Initial Evaluation}

Before initial color evaluation, a preliminary impression of the maxillary teeth was performed with a silicone impression material (Speedex; Vigodent S/A Ind. Com., Rio de Janeiro, RJ, Brazil). This impression served as a guide to standardize the color measurements by a Vita Easyshade spectrophotometer (Easyshade; Vident, Brea, CA, USA). A hole was made in the buccal surface of the silicon guide, which presented the same size of the active tip of the device. The selected position corresponds to the medium third of the right central incisive buccal surface. Color was determined with CIE L*a*b* parameters, where $L^{*}$ indicates luminosity, varying from 0 (black) to 100 (white).

\section{Randomization and Allocation Group}

Randomization was made by opaque envelopes containing the group identifications. Group allocation was revealed when opening these envelopes, at the time of brushing instructions.

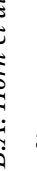

\section{Blinding}

The operator and patients were not blind to the allocation groups, but the data analyst was kept blind.

\section{Intervention}

The patients were randomly divided into 4 groups, according to the used dentifrice ( $n=15)$ : $\mathrm{GI}$ - Colgate Total 12 (Colgate-Palmolive, São Paulo, SP, Brazil); GII - Close-Up White Now (Unilever, São Paulo, SP, Brazil); GIII - Oral-B 3D White (Procter \& Gamble, São Paulo, SP, Brazil); GIV - Colgate Luminous White (Colgate-Palmolive, São Paulo, SP, Brazil). Table 1 shows the experimental groups and composition of each dentifrice.
The volunteers were instructed on how to use the dentifrices, the type of toothbrush was standardized as well as the brushing time. They were instructed to perform 3 daily brushings, for at least 2 to $3 \mathrm{~min}$, for 15 days. Change of dentifrice was not allowed during this period.

\section{Sample Size}

The sample size was calculated based on the mean (standard deviation) found in the control group. With $\alpha=0.05$ and power of $80 \%$, the minimum sample was 15 for each group to detect a significant difference between them.

\section{Final Evaluation}

The final color evaluation was performed after 15 days of treatment, in the same way as the initial evaluation. The CIE L*a*b* values were measured on each patient. The differences between the initial and final $L^{*}$ values were considered. Also, $\triangle E$ was calculated to fit the NBS (National Bureau of Standards) criteria, as follows:

$$
\begin{aligned}
& \Delta \mathrm{E}^{*} \mathrm{ab}=\left[\left(\Delta \mathrm{L}^{*}\right) 2+\left(\Delta \mathrm{a}^{*}\right) 2+\left(\Delta \mathrm{b}^{*}\right) 2\right] 0.5, \text { where: } \\
& \Delta \mathrm{L}^{*}=\mathrm{L}^{*} 1-\mathrm{L}^{*} 0 \text { (final values - initial values) } \\
& \Delta \mathrm{a}^{*}=\mathrm{a}^{*} 1-\mathrm{a}^{*} 0 \text { (final values - initial values) } \\
& \Delta \mathrm{b}^{*}=\mathrm{b}^{*} 1-\mathrm{b}^{*} 0 \text { (final values - initial values). }
\end{aligned}
$$

\section{Statistical Analysis}

Data were analyzed by ANOVA for independent samples and $t$ test for paired samples (initial and final values for each group), 95\% confidence interval and $\alpha=0.05$.

\section{Results}

Table 2 shows the initial and final $L^{*}$ values (luminosity) of each experimental group. For GI, GII and GIII, no significant differences were observed in 15 days. For GIV, a significant increase in $L^{*}$ value was obtained $(p=0.01)$.

$\triangle \mathrm{E}$ was also calculated in order to analyze NBS criteria, which verify visible and non-visible human eyes alterations. These criteria demonstrated that GI, GII and GIII did not

Table 1. Experimental groups, dentifrices (manufacturer/batch number) and composition

\begin{tabular}{lcc}
\hline Group & Material (manufacturer) & Composition \\
\hline Gl & Colgate Total 12, & Water, hydrated silica, sodium lauryl sulphate, Sodium hydroxide, Sodium \\
& Colgate-Palmolive & fluoride $(0.32 \%)$, Triclosan, sodium saccharin, titanium dioxide. \\
Gll & Close Up White Now, & Water, sorbitol, hydrated silica, sodium lauryl sulphate, sodium fluoride \\
& Unilever Brazil & $(0.32 \%)$, sodium saccharin, trisodium phosphate, dipentene. \\
Glll & Oral B 3D White/Procter & Sodium fluoride (1450 ppm fluoride), water, hydrated silica, sorbitol,
\end{tabular}

GIV

$$
\begin{aligned}
& \text { Colgate Luminous White/ } \\
& \text { Colgate-Palmolive }
\end{aligned}
$$

Water, hydrated silica, sorbitol, pentasodium triphosphate, tetrapotassium pyrophosphate, sodium lauryl sulfate, polyethylene, cocamidopropyl betaine, sodium saccharin, sodium hydroxide, sodium fluoride (1100 ppm fluoride), titanium dioxide, blue \#1 aluminum lac 
present alterations $(0.25,0.48$ and 0.29 , respectively), and GIV presented slight alteration (1.15), not visible for human eyes.

\section{Discussion}

Few studies in the literature have evaluated the relationship between brushing with toothpastes proposed to bleach vital teeth and the efficacy of these products to obtain significant results $(6,8-10,13-15)$. However, there were some randomized clinical trials that evaluated the effect of different whitening toothpastes $(6,8,13,19)$.

Although peroxide-based bleaching is an established method for bleaching, its use in dentifrice is restricted. Beyond the changes caused in the dentifrice formula, the lack of feasibility is also due to the fact that peroxide hydrogen must be applied with a barrier, allowing a long contact time, which did not happen with the toothpastes $(18,19)$. According to Anton et al $(8)$, dentifrices containing hydrogen peroxide, although they produce certain increase in the $L^{*}$ parameter, they cannot reduce the pigmentation of the yellow color ( $b^{*}$ parameter) with clinical efficacy. However, Sharma et al (17) concluded that a dentifrice containing $1.0 \%$ hydrogen peroxide and cleaning high performance silica showed statistically significant results for the removal of extrinsic stains compared with conventional toothpaste.

The findings of this study corroborate the results obtained by other studies that disagree about the potential of whitening toothpastes to actually reduce the discoloration of tooth structure, showing that toothpastes act removing extrinsic stains due to higher abrasiveness of these products (6-10). Analyzing the composition of dentifrices selected for this study, it may be observed that they do not contain any substance able to deliver oxygen and subsequent bleaching action; they contain only highperformance abrasives such as hydrated silica.

Analyzing the $L^{*}$ values (luminosity), it was observed that the toothpastes Colgate Total 12, Close Up White Now and Oral B 3D White were not effective for tooth

Table 2. Mean (standard deviation) of $\mathrm{L}^{*}$ values, $\mathrm{p}$ values, mean difference and confidence interval $(\mathrm{Cl})$ from each group

\begin{tabular}{lcccc}
\hline & Initial & Final & p value & $\begin{array}{c}\text { Mean difference } \\
\text { and } \mathrm{Cl}(95 \%)\end{array}$ \\
\hline Gl & $82.9(4.9)^{\mathrm{Aa}}$ & $84.1(6.3)^{\mathrm{Ba}}$ & 0.31 & $-1.1(-3.6$ to 1.2$)$ \\
Gll & $83.9(5.8)^{\mathrm{Aa}}$ & $84.6(6.1)^{\mathrm{Ba}}$ & 0.43 & $-0.7(-2.6$ to 1.1$)$ \\
Glll & $83.9(7.2)^{\mathrm{Aa}}$ & $84.2(7.1)^{\mathrm{Ba}}$ & 0.64 & $-0.3(-2.0$ to 1.3$)$ \\
GIV & $86.4(3.4)^{\mathrm{Aa}}$ & $88.2(2.8)^{\mathrm{Bb}}$ & 0.01 & $-1.7(-3.2$ to -0.3$)$ \\
\hline
\end{tabular}

*Different lowercase letters in columns and uppercase letters in rows indicate statistically significant difference $(p<0.05)$. whitening, as they did not present alterations in $\mathrm{L}^{*}$ values, comparing the initial and the final conditions. On the other hand, analyzing the luminosity values of Colgate Luminous White, statistically significant results were obtained, which may be explained by the different abrasive contents of the dentifrice: silica with high performance cleaning and polyphosphates. However, according to NBS criteria, $\triangle \mathrm{E}$ for this group was 1.15, which means a slight alteration, not perceived by the human eye.

Extrinsic stains on the tooth surface may be removed by the abrasive action; for intrinsic stains removal, whitening techniques are required, based on hydrogen or carbamide peroxide agents. These techniques depend on the concentration of the products, application technique and contact time with the tooth surface (18). Based on this, use of whitening toothpastes that promise fast and convenient bleaching did not provide satisfactory effects, probably due to the absence of hydrogen agents.

Based on these results, it may be concluded that brushing with the toothpastes evaluated in this study was not effective to produce a significant bleaching effect on dental enamel, with the exception of Colgate Luminous White toothpaste. However, analyzing the $\Delta$ E values, a slight color alteration was observed, not visible to the patient. Further clinical studies should be performed to evaluate the real effect of these whitening toothpastes and other brands, to reach a definite conclusion concerning this matter.

\section{Resumo}

Este estudo clínico randomizado avaliou o potencial clareador de cremes dentais disponiveis no mercado. Materiais e Métodos: Foram selecionados 60 pacientes, os quais foram divididos aleatoriamente em 4 grupos $(n=15)$ : GI - controle - Colgate Total 12; GII- Close-up White Now; GIII - Oral-B 3D White; GIV - Colgate Luminous White. Foram realizadas 3 escovações diárias pelo tempo de 2 a 3 minutos, durante um periodo de 15 dias. Os pacientes tiveram a cor de seus dentes avaliados antes e após o término do tratamento através do espectrofotômetro Vita EasyShade (escala CIE L*a* $\left.{ }^{*}\right)$ Os valores de $L^{*}$ foram analisados por ANOVA um fator para amostras independentes e teste $t$ para amostras pareadas. $\Delta \mathrm{E}$ também foi calculado para verificar alterações de cor, de acordo com os critérios NBS. A média (desvio padrão) dos valores iniciais foi: GI: $82,9(4,9)$; GII: 83,9(5,8); GIII: 83,9(7,2); GIV: $86,4(3,4)$; e os valores finais - GI: $84,1(6,3)$; GII: $84,6(6,1)$; GIII: $84,2(7,1)$; GIV: $88,2(2,8)$, concluindo-se que os dentifrícios analisados neste estudo não apresentaram ação clareadora sobre dentes vitais, com exceção do dentifrício Colgate Luminous White, porém de acordo com os critérios do NBS, não houve alteração visivel a olho nu para nenhum dos grupos.

\section{References}

1. Tin-Oo M, Saddki N, Hassan N. Factors influencing patient satisfaction with dental appearance and treatment they desire to improve aesthetics. BMC Oral Health 2011;11:6.

2. Marshall K, Berry T, Wollum J: Teeth whitening: Current status. Compend Contin Educ Dent 2010;31:486-492.

3. Li Y. Safety controversies in tooth bleaching. Dent Clin North Am 2011;55:255-263.

4. Demarco FF, Meireles SS, Masotti AS. Over-the-counter whitening agents: a concise review. Braz Oral Res 2009;23 Suppl 1:64-70. 
5. Magalhães AC, Moron BM, Comar LP, Buzalaf MA. Rational use of dentifrices. RGO 2011;59:615-625.

6. Claydon NCA, Moran J, Bosma ML, Shirodaria S, Addy M, Newcombe R. Clinical study to compare the effectiveness of a test whitening toothpaste with a commercial whitening toothpaste at inhibiting dental stain. J Clin Periodontol 2004;31:1088-1091.

7. Antón AS, Lima MJ, Araújo RP. Hydrogen peroxide toothpaste: Whitening action? Rev Odonto Cienc 2009;24:161-167.

8. Torres CR, Perote LC, Gutierrez NC, Pucci CR, Borges AB. Efficacy of mouth rinses and toothpaste on tooth whitening. Oper Dent 2013;38:57-62.

9. de Araújo DB, Silva LR, Campos Ed, Correia de Araújo RP. In vitro study on tooth enamel lesions related to whitening dentifrice. Indian J Dent Res $2011 ; 22: 770-776$.

10. Hilgenberg SP, Pinto SC, Farago PV, Santos FA, Wambier DS. Physicalchemical characteristics of whitening toothpaste and evaluation of its effects on enamel roughness. Braz Oral Res 2011;25:288-294.

11. Kwon SR, Wang J, Oyoyo U, Li Y. Evaluation of bleaching efficacy and erosion potential of four different over-the-counter bleaching products. Am J Dent 2013;26:356-360.

12. Moran J, Claydon NCA, Addy M, Newcombe R. Clinical studies to determine the effectiveness of a whitening toothpaste at reducing stain (using a forced stain model). Int J Dent Hyg 2005;3:25-30.

13. Walsh TF1, Rawlinson A, Wildgoose D, Marlow I, Haywood J, Ward
JM. Clinical evaluation of the stain removing ability of a whitening dentifrice and stain controlling system. J Dent 2005;33:413-418.

14. Novais RC, Toledo OA. In vitro study of dental enamel alterations after exposing to a bleaching agent. J Bras Clin Estet Odontol 2000;4:48-51.

15. Lima FG, Rotta TA, Penso S, Meireles SS, Demarco FF. In vitro evaluation of the whitening effect of mouth rinses containing hydrogen peroxide. Braz Oral Res 2012;26:269-274.

16. Schulz KF, Altman DG, Moher D. CONSORT group. CONSORT 2010 Statement: updated guidelines for reporting parallel group randomized trials. Int J Surg 2011;9:672-677.

17. Sharma N, Galustians HJ, Qagish J, Rustogi K, Zhang YP, Petrone ME, et al.. Comparative tooth whitening and extrinsic tooth stain prevention efficacy of a new dentifrice and a commercially available tooth whitening dentifrice: six-week clinical trial. J Clin Dent 2004;15:52-57.

18. Joiner A, Pickles MJ, Matheson JR, Weader E, Noblet L, Huntington E. Whitening toothpastes: effects on tooth stain and enamel. Int Dent J 2002;52:424-430.

19. Gallo JR, Burgess JO, Ripps AH, Bell MJ, Mercante DE, Davidson JM. Evaluation of $30 \%$ carbamide peroxide at-home bleaching gels with and without potassium nitrate - A pilot study. Quintessence Int $2009 ; 40: 1-6$ 